\title{
Genetic and antigenic analysis of mink's immunoglobulin G Fc region
}

\author{
LEI JIANG*, LI LI*, CUI ZHAO, XIAO-RU PANG, QIANG SHEN, WEI-SHAN CHANG, JING ZHAI
}

*Lei Jiang and Li Li contributed equally to this work.

Shandong Agricultural University, Taian, PR China

\begin{abstract}
Mink's immunoglobulin (Ig) G Fc gene was cloned, the gene was analyzed by phylogenetic analysis, and western blot was done to prove that the detection of distemper and canine parvovirus in dogs and minks can be universal. In order to get the certain length of $F c$ segment gene, a pair of primers is designed, which according to the Fc segment gene sequences of mink's IgG (L07789) published by GenBank, extracted total RNA from the spleen of minks and amplified it by RT-PCR. The results showed that the Fc segment gene contained $606 \mathrm{bp}$. Then it was sequenced after the amplified fragments were cloned into the vector PEasy-T1. Then the genetic evolution was analyzed. An antibody hybridization test was done through western blot. The results showed that nucleotide sequence homologies between minks and canines were 85\%, and amino acid sequence homologies between minks and canines were $80.5 \%$. Mink IgG heavy chain can effectively combine to anti-dog IgG by western blot. It was concluded that mink's and dog's IgG Fc had the closest relationship in mammalian through the analysis of the genetic evolution. Based on the above analysis and related literature, we concluded that we could detect mink diseases with a dog diagnosis reagent, or treat mink diseases with dog antiserum.
\end{abstract}

Key words: mink, IgG Fc gene, genetic analysis, western blot detection.

(Centr Eur J Immunol 2014; 39 (1): 36-39)

\section{Introduction}

In recent years, the scale of special animal breeding in China has continued to expand, the quantity of mink breeding has reached a certain scale, but currently the epidemic diseases among the groups of minks are viral diseases, such as canine distemper, canine parvovirus disease [1]. At present, a virus detection kit and colloidal gold test strip for the minks are not yet popular, and as a result, rapid detection of diseases of the minks cannot be carried out conveniently. Several viral diseases in dogs also occur in minks, and canine disease diagnostic market has become perfect, so that the possibility of using dogs' detection reagents to detect corresponding viral diseases in minks has an important significance.

Fc is a significant domain of immunoglobulins [2, 3]. It is related to the species specific to the antibody. Immunoglobulin G Fc fragment not only has the ability to activate the complement system, but also the ability to induce the binding of the antigen-antibody complex and the antigen-presenting cell through the Fc receptor (FcR) [4]. It can also promote the phagocytosis of antigen-presenting cells to foreign antigens in the receptor-induced ones, and thus stimulate the cellular immune response of the body to specific antigens [5, 6]. In this study we extracted RNA from mink spleen, then mink IgG Fc gene was cloned, and the genetic evolution of this sequence was analyzed. Mink, canine, mice and chicken IgG cross-reactivity was detected based on western blot. It provides a theoretical basis for guiding clinical mink disease immune detection and serology treatment.

\section{Material and methods}

\section{Sample collection and tissue preparation}

The minks were purchased from a mink farm, Zhucheng, China. Spleen was harvested and frozen in the fridge $\left(-20^{\circ} \mathrm{C}\right)$.

\section{Total RNA isolation and synthesis of cDNA}

Total RNA samples were extracted from spleens using Trizol (TransGen) and the cDNA pool was obtained using the PrimScript RT reagent Kit (TaKaRa).

\section{RT-PCR and sequencing}

A pair of homologous primers (Table 1) was designed by DNASTAR 5.0 software with respect to the minks 
(GenBank: L07789.1). With the primers, a cDNA fragment was amplified through RT-PCR using the first strand cDNAs as templates. The PCR reaction was performed under the following conditions in a thermal cycle: initial denaturation at $94^{\circ} \mathrm{C}$ for $5 \mathrm{~min} ; 30$ cycles of denaturation at $94^{\circ} \mathrm{C}$ for $30 \mathrm{~s}$; annealing at $55^{\circ} \mathrm{C}$ for $30 \mathrm{~s}$ and extension at $72^{\circ} \mathrm{C}$ for $10 \mathrm{~min}$. Polymerase chain reaction (PCR) products were analyzed by electrophoresis in $1 \%$ agarose, and purified by Agarose Gel DNA Extraction Kit (Shanghai Sangon Biotech Co., Ltd.). The products were cloned by Peasy-T1(TransGen) and sent to Shanghai Sangon Biotec Co., Ltd. for sequencing.

\section{Multiple alignment and phylogenetic sequence analysis}

The nucleotide sequence of mink IgG-Fc fragment, along with that of American minks, canines, mice and chicken from GenBank, were aligned by DNAstar software. Phylogenetic analysis was carried out utilizing DNAMAN5.2 software.

\section{SDS-PAGE and Western-blot}

Different animal IgG (Y) (Beijing solarbio Co., Ltd.) was quantitatively diluted, then the samples and the Loading Buffer were added to boiling water at a ratio of $1: 1$ and boiled for $10 \mathrm{~min}$. Concentration of the stacking gel was $5 \%$, concentration of the separating gel was $15 \%$, wet transfer was carried out overnight. The cellulose membrane was closed by $5 \%$ skim overnight, and rinsed 2 times, 5 min each time. Rabbit anti-dog $\operatorname{IgG}$ was diluted 200 -fold, $10 \mathrm{ml}$ of diluent was added, slowly incubated at room temperature for $3 \mathrm{~h}$, rinsed for $10 \mathrm{~min}$ by TBST for a total of 5 times. At last it was developed in a darkroom by HRP-DAB and was observed after $3 \mathrm{~min}$.

\section{Results}

\section{Molecular cloning and analysis of mink IgG-Fc}

A cDNA fragment of mink IgG-Fc fragment of 606bp (Fig. 1) was obtained from single RT-PCR which was identified from the spleen cDNA library of mink. It encoded a protein 202 amino acids in length.

\section{Alignment and phylogenetic analysis}

The deduced amino acid sequence of IgG-Fc was compared with those of American minks, canines, mice and chicken using DNAMAN (Fig. 2). The phylogenetic tree was constructed from the deduced mink IgG-Fc and the $\operatorname{IgG}(\mathrm{Y})$ sequences from several avians and mammalians using software DNAMAN 5.0. The result revealed that the highest homology of minks was with canines, and avian IgY-Fc which formed a monophyletic group distinct from mammalian IgG-Fc (Fig. 3).
Table 1. Conserved sequence amplification PCR and 3 'race products using forward and reverse primer sequences

\begin{tabular}{ll}
\hline Primer name & Primer sequences \\
\hline Mink Fc & 5'-ctcgagcagtcttcatgttccccc-3'(f) \\
\hline & 5'-aagcttgatggtcttctgcgtgtggt-3'(s) \\
\hline
\end{tabular}

\section{The genetic variation analysis on gene and amino acids of $\operatorname{IgG}(\mathbf{Y})$-Fc of different animals}

The genetic variation analysis of minks (sequencing), American minks, canines, mice and chicken's gene and amino acids of $\operatorname{IgG}(\mathrm{Y})-\mathrm{Fc}$ was shown in Table 2 . The results showed that nucleotide sequence homologies between minks (sequencing) and American minks were 99\%, and amino acid sequence homologies between minks and American minks were $97.5 \%$. The highest nucleotide sequence homologies between minks and heterogeneous animals were $85 \%$ (canine), and the highest amino acid sequence homologies between minks and heterogeneous animals were $80.5 \%$.

\section{SDS-PAGE western blot}

In Fig. 4, a heavy chain of $\operatorname{IgG}(\mathrm{Y})$ of different animals could be clearly seen. The heavy chain of minks, mice and

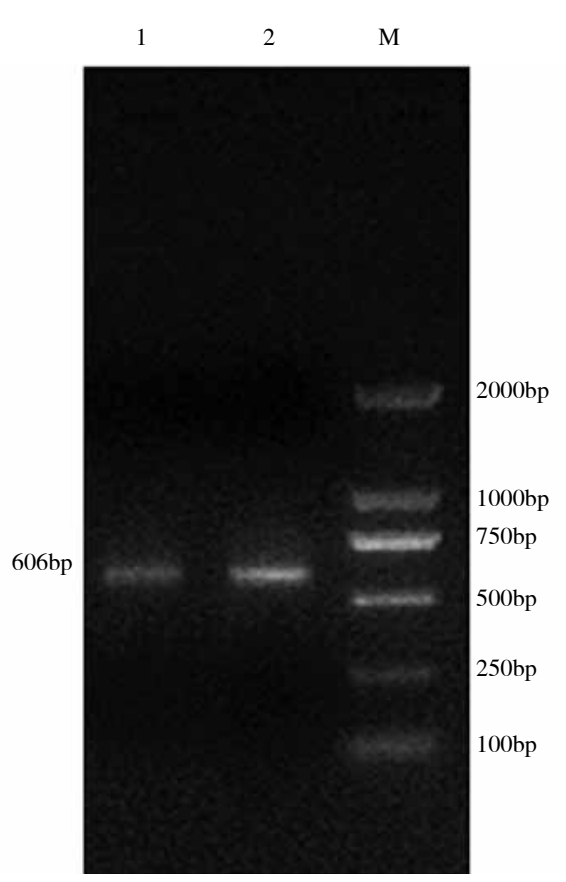

Fig. 1. RT-PCR amplified the result of mink Fc gene M: DL 2000 Marker; 1.2: RT-PCR product of mink IgG Fc 
Table 2. The genetic variation analysis on different animal's Fc genes and amino acids

\begin{tabular}{cccccc}
\hline $\begin{array}{l}\text { NT } \\
\text { AA }\end{array}$ & 1 & 2 & 3 & 4 & 5 \\
AA & & 85.0 & 52.8 & 66.3 & 99.0 \\
\hline 1 & & 52.2 & 66.8 & 84.9 \\
\hline 2 & 80.5 & 34.5 & 49.9 & 53.3 \\
\hline 3 & 32.2 & 58.5 & 29.8 & 66.1 \\
\hline 4 & 59.0 & 80.0 & 33.7 & 60.0 &
\end{tabular}

Note: NO. 1-5 represent the mink IgG Fc gene amplified in this test, canines (GenBank NO.: DQ452014), chicken (GenBank NO.: X07174), mice (GenBank NO.: BC092049), American minks (GenBank NO.: L07789).

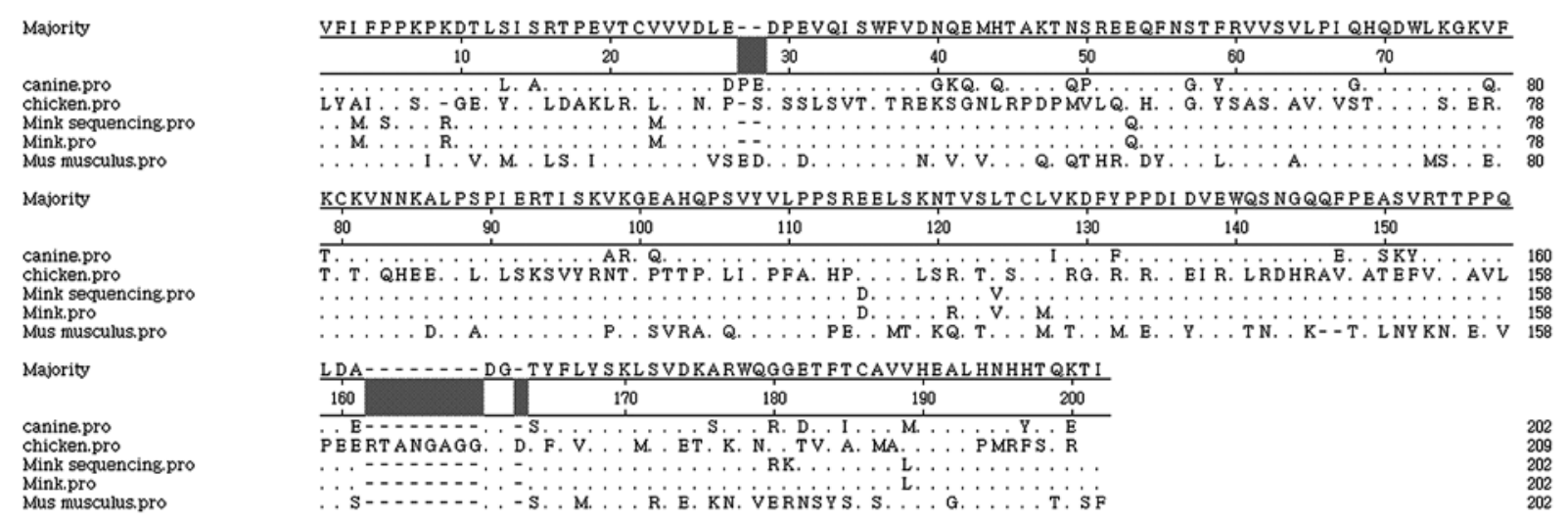

Fig. 2. Alignment of mink's amino acid sequence Note: The gene which was amplified was named "Mink sequencing". The black spot reveals the conserved amino acid residues

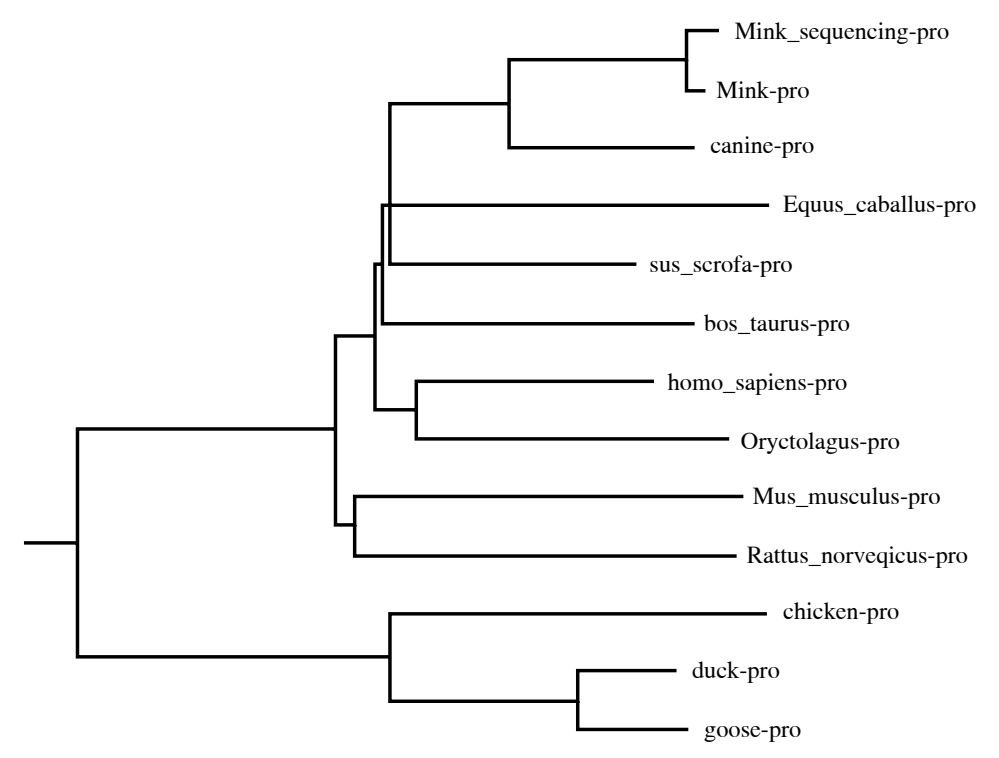

Fig. 3. Phylogenetic tree of $\operatorname{IgG}(\mathrm{Y})$ amino acid sequences of three poultry and several mammalian species 


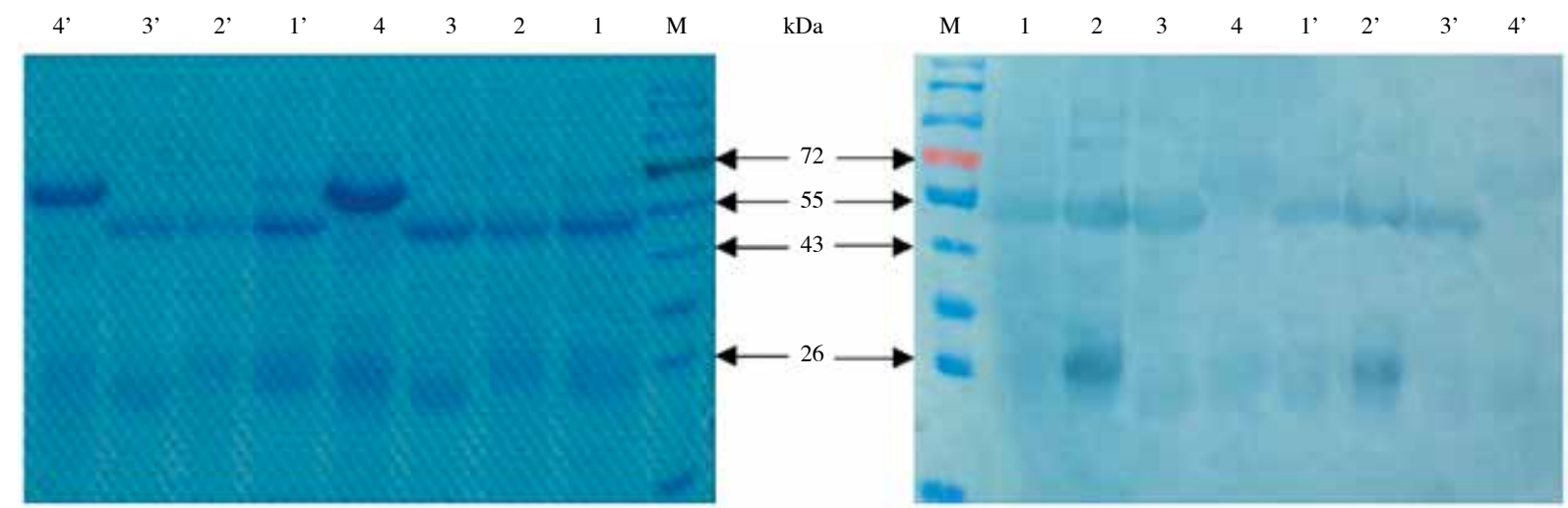

Fig. 4. SDS-PAGE pattern and western blot detection of different animal's IgG (Y) Note: 1 . Mink IgG $(1 \mu \mathrm{g} / \mu \mathrm{l}), 2$. Canine $\operatorname{IgG}(1 \mu \mathrm{g} / \mu \mathrm{l}), 3$. Mouse $\operatorname{IgG}(1 \mu \mathrm{g} / \mu \mathrm{l}), 4$. Chicken $\operatorname{IgY}(1 \mu \mathrm{g} / \mu \mathrm{l}), 1^{\prime}$. Mink IgG $(0.5 \mu \mathrm{g} / \mu \mathrm{l}), 2^{\prime}$. Canine $\operatorname{IgG}(0.5 \mu \mathrm{g} / \mu \mathrm{l}), 3$ '. Mouse IgG $(0.5 \mu \mathrm{g} / \mu \mathrm{l}), 4$ '. Chicken IgY $(0.5 \mu \mathrm{g} / \mu \mathrm{l})$

canines was about $55 \mathrm{KD}$, the heavy chain of chicken was about $67 \mathrm{KD}$. It also showed that the anti-dog IgG-HRP could be reacted with $\operatorname{dog} \operatorname{IgG}$ heavy chain and light chain. Anti-dog IgG-HRP and mink IgG had cross-reactivity to a certain extent, and the cross-reactivity response with chicken was very weak.

\section{Discussion}

The antigenicity of the antibody itself mainly depends on the Fc fragment of the antibody heavy chain. The constant region gene of the heavy chain is relatively conservative, so the analysis of the homology of different animal IgG heavy chain gene can reflect whether the antigenicity of the different animal antibody has intersectionality or not. In this study, we cloned the active mink's $\mathrm{IgG} F \mathrm{Fc}$ gene, and we analysed the genetic evolution. We obtained the evolutionary tree and sequences' comparison chart. The analysis of gene and amino acid showed that there was a certain extent of homology among IgG Fc of different animals. Mammals and birds could be seen that they belong to two branches of the evolutionary tree, and minks had the closest relationship with dogs. We firstly proved that mink IgG heavy chain can effectively combine to anti-dog IgG by western blot effectively. Therefore, we conclude that the diagnosing of mink diseases by dog diagnosis reagent is feasible. Through clinical practice we have also proved that the diagnostic SMZ-strip of dog's canine distemper, parvovirus could be used on minks [7, 8]. From clinical practice, we got that we could treat mink's distemper with serum of rehabilitated dogs' distemper.

In this experiment, a variety of software analysis and western blot analysis demonstrated that dogs' test kit can be applied to the body of the minks. And this study provided a theoretical basis for guiding the diagnosing of clinical disease of minks, it also laid the foundation for the research of antigenic gene and immunotherapy of antigenic protein.

Authors declare no conflict of interest.

This work was supported by the project J08LF60 of the Shandong (China) Provincial Department of Education.

\section{References}

1. Sidhu MS, Husar W, Cook SD, et al. (1993): Canine distemper terminal and intergenic non-protein coding nucleotide sequence: completion of the entire CDV genome sequence. Virology 193: 66-72.

2. Jefferis R, Lund J, Pound JD (1998): IgG-Fc-mediated effector functions: molecular definition of interaction sites for effector ligands and the role of glycosylation. Immunol Rev 163: 59-76.

3. Morgan EL, Thoman ML, Weigle WO (1981): Enhancement of T lymphocyte functions by $\mathrm{Fc}$ fragments of immunoglobulins. I. Augmentation of allogeneic mixed lymphocyte culture reactions requires I-A-or-I-B subregion differences between effector and stimulator cell populations. J Exp Med 153: 1161-1172.

4. Teplyakov A, Zhao Y, Malia TJ (2013): IgG2 Fc structure and the dynamic features of the $\mathrm{IgG} \mathrm{CH} 2-\mathrm{CH} 3$ interface. Mol Immunol 56: 131-139.

5. Ferrone CR, Perales MA, Goldberg SM (2006): Adjuvanticity of plasmid DNA encoding cytokines fused to immunoglobulin Fc domains. Clin Cancer Res 12: 5511-5519.

6. Regnault A, Lankar D, Lacabanne V (1999): Fc gamma receptor-mediated induct ion of dendritic cell maturation and major histocompatibility complex class I restricted antigen presentation after immune complex internalization. J Exp Med 189: 371-380.

7. Chappuis G (1995): Control of canine distemper. Vet Microbiol 44: 351-358.

8. Blixenkrone-Mřller M, Pedersen IR, Appel MJ, Griot C (1991): Detection of IgM antibodies against canine distemper virus in dog and mink sera employing enzyme-linked immunosorbent assay (ELISA). J Vet Diagn Invest 3: 3-9. 